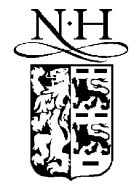

ELSEVIER
Available online at www.sciencedirect.com

science $\mathcal{D}$ Directo

Applied Surface Science 216 (2003) 2-7

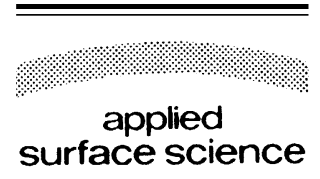

www.elsevier.com/locate/apsusc

\title{
The National Si-Soft Project
}

\author{
Chun-Yen Chang ${ }^{\mathrm{a}, \mathrm{b}}$, Charles V. Trappey ${ }^{\mathrm{b}, *}$ \\ ${ }^{\mathrm{a}}$ National Academy of Engineering, USA \\ ${ }^{\mathrm{b}}$ Department of Management Science, National Chiao Tung University, Hsinchu, Taiwan
}

\begin{abstract}
Taiwan's electronics industry emerged in the 1960s with the creation of a small but well planned integrated circuit (IC) packaging industry. This industry investment led to bolder investments in research, laboratories, and the island's first semiconductor foundries in the 1980s. Following the success of the emerging IC manufacturers and design houses, hundreds of service firms and related industries (software, legal services, substrate, chemical, and test firms among others) opened for business and completed Taiwan's IC manufacturing supply chain. The challenge for Taiwan's electronics industry is to take the lead in the design, manufacture, and marketing of name brand electronic products. This paper introduces the Si-Soft (silicon software) Project, a national initiative that builds on Taiwan's achievements in manufacturing (referred to as Si-Hard or silicon hardware) to launch a new wave of companies. These firms will contribute to the core underlying technology (intellectual property) used in the creation of electronic products.
\end{abstract}

(C) 2003 Elsevier Science B.V. All rights reserved.

Keywords: Si-Soft; Taiwan electronics industry; Electronics design

\section{The history of Taiwan's IC industry}

Taiwan's integrated circuit (IC) industry began in the 1960s with IC packaging, the industry process whereby pre-manufactured wafers are packed into lead-frames and substrates to form the chips used in computers and other electronic devices. Packaging involves molding the chips into small components that can be mounted on boards that are fitted into electronic devices such as personal computers. Packaging requires less technology and more labor than wafer fabrication and much, much less technology than logic design. Since Taiwan had little IC technology in the

\footnotetext{
* Corresponding author. Tel.: +886-3-572-7686; fax: +886-3-571-3796.

E-mail addresses: cyc@cc.nctu.edu.tw (C.-Y. Chang), trappey@cc.nctu.edu.tw (C.V. Trappey).
}

1960s, packaging was used as a test case to demonstrate that there was a viable and sustainable market. By 1970, the government supported several laboratories to transfer the necessary technologies to build the fabrication and manufacturing facilities for an upstream supply chain. By the 1980s, IC fabrication sites and IC design laboratories completed the supply chain, forming the first nascent IC industry in the Hsinchu science-based industrial park [1].

\subsection{0s-IC packaging}

During the 1960s, Taiwan's Gross National Product was about US\$237 per capital. Industry was concentrated in commerce $(46 \%)$ and manufacturing $(31 \%)$. Although agricultural contributed $23 \%$ to the economy, the manufacturing sector was developing and creating a shift in the economic structure. The trend at 
the time was to build the textile, plastic, glass, and paper industries through government incentives. The greatest incentives were given to export oriented companies that pursued new technology. A special industrial zone was setup in Kaoshiung in 1966 to facilitate the export of domestically manufactured goods and to reduce the trade deficit. Kaoshiung Electronics Company and Phillips Taiwan setup facilities in the Hsinchu science park and were the first to package ICs.

\subsection{0s-ITRI's electronics laboratory}

The first global oil crisis occurred during 1973, causing a $23 \%$ rise in domestic prices, an inflation rate of $41 \%$, and a decline in the economic growth rate to one percent. During the 1970s, Taiwan's agricultural sector was in decline and although the manufacturing sector had grown and was a major contributor to the economy, Taiwan's overall exports were badly hit by the rise in inflation. The government sought new ways to stimulate the economy by increasing public spending on six major transportation projects. In addition, a 10-year national development plan was formulated to improve infrastructures and facilities, to speed up industrial modernization, and to build heavy industries such as steel, copper, iron, aluminum, shipbuilding, automobiles, machinery, and petrochemicals.

The development of Taiwan's IC industry began in 1974 when the Industrial Technology Research Institute founded the Electronic Research and Service Organization (ERSO). ERSO was the launch point for the IC manufacturing industry and provided the basic laboratories and personnel for the transfer of technology. A key milestone for ERSO was a 1976 project with RCA to transfer CMOS IC technology. The project was instrumental in demonstrating the feasibility of industry and government working together to build a new industrial sector. During 1979, regulations governing the establishment of science and industrial parks were written and the first IC industries began to build facilities in Hsinchu.

\subsection{0s-IC manufacturing and design industries launched}

During the 1980s, Taiwan was affected by the global recession, resulting in falling demand for Taiwan's products and a decrease in private investment.
With government backing, the United Microelectronics Corporation (UMC) was founded and represents the first step towards moving the electronics industry from IC packaging into IC manufacturing. Taiwan continued to adjust the industrial structure by promoting the information and electronics industry through incentives and regulations. The regulation called "Encouraging Investment Conditions and Requirements" had a positive effect on the investment climate and helped to build the electronics sector in spite of the global recession.

When America's telephone monopoly was dismantled, the newly formed regional companies began to send orders to Taiwan firms to manufacture telephone parts and telecommunications equipment. Orders from the "Baby Bell" companies helped UMC and others in the science park survive a difficult start-up period during adverse economic conditions. The Taiwan Semiconductor Manufacturing Company (TSMC) was established in 1987 and began the island's first IC design business and created the dedicated semiconductor foundry industry. As a result of the formation of UMC and TSMC, the foundation for the IC industry was completed. Taiwan began making computers, PC peripherals, and communications devices and to create products that boosted the demand and increased overall IC production.

\subsection{0s—building the IC industry supply chain}

During the 1990s, Taiwan aggressively developed the electronics industry and added support industries to the supply chain. After 30 years of development, the design and manufacturing supply chain system was completed with over 150 related IC companies, as shown in Fig. 1. The workforce exceeded 50,000 employees, most of whom are college educated and bi-lingual. Investment commitments at the end of the 1990s almost reached US $\$ 80$ billion, setting a record for growth and using up all of the land in the Hsinchu industrial park. The IC firms began planning and building facilities in the Tainan science-based industrial park.

Research and development investments in the global IC design industry typically account for $11 \%$ of a company's total expenses. By comparison, Taiwan's IC R\&D expenses accounted for less than 5\% since local companies are mainly large-volume original 


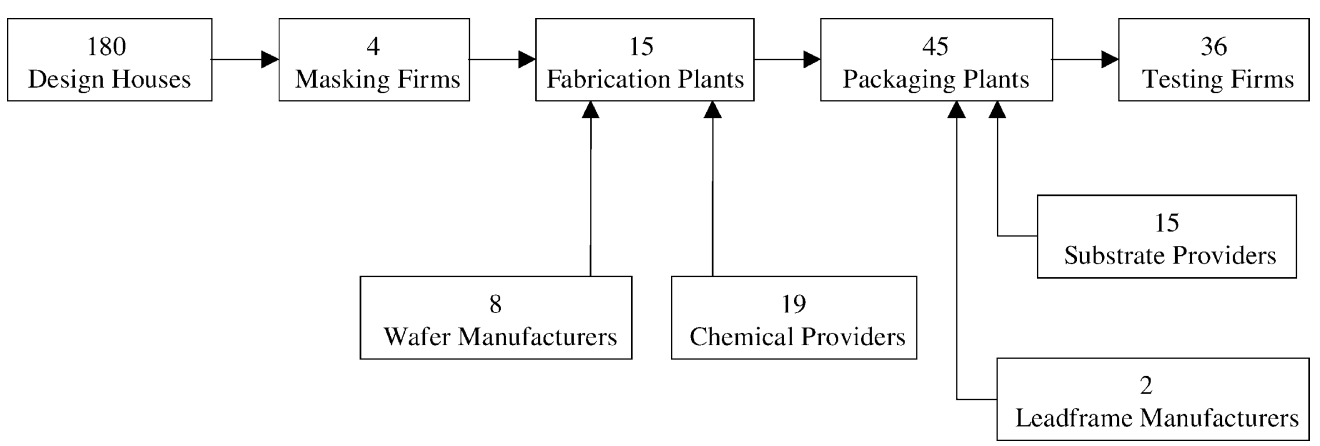

Fig. 1. The ERSO/ITRI (2002) diagram of the Taiwan IC industry supply chain.

equipment manufacturing (OEM) producers. The next decade of development will show greater emphasis on the creation of intellectual property and greater investment in research [2].

\subsection{0 and beyond-innovation, design and creation of intellectual property}

The objective of the next 10 years is to foster the design and creation of intellectual property based on Taiwan's existing strengths in the areas of hardware and manufacturing of electronic components (Fig. 2).

The long-term plan of the Si-Soft (silicon software) Project is to reach NT\$ 300 billion revenue from the development of innovative products and innovative design companies.

\section{Introduction to Taiwan's National Si-Soft Project}

Taiwan has developed one of the most comprehensive semiconductor industries in the world with an infrastructure that includes design houses, semiconductor and other component manufacturing facilities, masking process plants, testing companies, and a wide range of component packaging lines. Companies comprising the semiconductor supply chain are globally linked, meaning that they are integral to the worldwide production of electronic parts, components, and equipment. The state of development for the semiconductor industry has reached a high level of efficiency with production that often surpasses expectations of quality and delivery time. As a result, Taiwan's foundries are

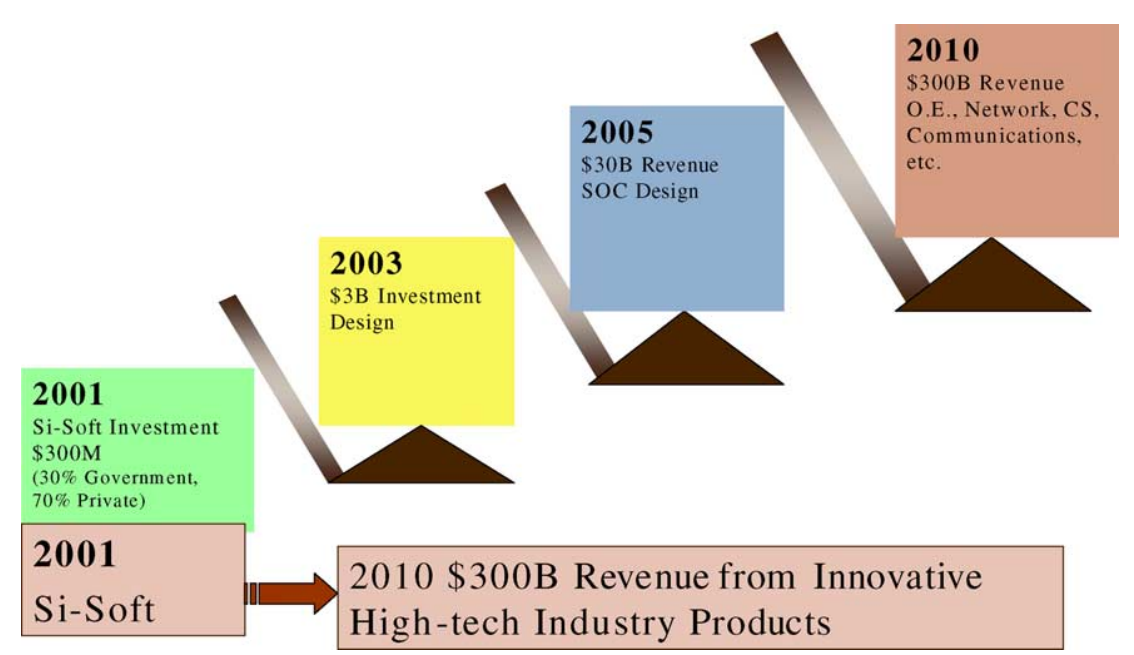

Fig. 2. Si-Soft builds opportunities for knowledge workers including designers, engineers, programmers, managers, and legal experts. 
ranked first among competitors and hold $76 \%$ of the global market share. Fabless design houses are ranked second (after the US) and hold a 20\% market share, while testing and packaging are ranked first with a $35 \%$ market share.

Taiwan's electronics industry has experienced success in the area of electronics manufacturing and foundry based production of semiconductors since the 1980s. However, innovative design and the creation of brand name products have not reached the desired level of development. Undoubtedly, there have been overwhelming successes with innovation and brand name development and the cases of Acer, TSMC, UMC, and others are frequently cited. These companies, through good management and excellent research and development, have become global members of the electronics supply chain and are producing extraordinary amounts of goods and services. The limitation is that not enough of Taiwan's electronics companies are driving the designs for global consumer products and contributing to the core underlying technology (intellectual property) used in the creation of these products [3].

The long term objective and vision of the Si-Soft Project is to promote the creation of intellectual property by Taiwan's design houses and to lead the third wave of industrial development where Taiwan companies are not only important members of the global electronics supply chain but are direct contributors to the design, manufacture, and marketing of name brand electronic products and consumer goods. Taiwan has as its strengths the ability to design, build and operate the world's best semiconductor foundries and packaging factories [4]. Across the electronics industry supply chain, Taiwan has created successful international firms. However, these business successes lag behind achievements in the Silicon Valley, the world center for semiconductor design and innovation.

Europe, Japan, Korea, the US and Taiwan are transferring design and manufacturing technology to the developing China market, each according to their specialty. The impact to Taiwan is that industry's traditional role as an OEM center is changing, businesses are facing new challenges, and entrepreneurs are recognizing new opportunities. Si-Soft addresses this marketplace dynamic through the strategic restructuring of industrial development. Taiwan's manufacturing strength must be used as an engine to drive new designs. Whereas the past emphasis has been on production, the new emphasis is being placed on the design of products and product components and the final step will be to emphasize the marketing of Taiwan brands.

The desired outcome where Taiwan firms move from manufacturing to brand and product development depends upon the successful integration of the design chain. Platform service development, such as the sale and re-use of virtual components, the enhanced access to software programming talent, and the training of a larger pool of knowledge workers and design artists is ongoing across Taiwan. A strong platform of services provided by knowledge workers and designers is the base for new products that can be rapidly manufactured by Taiwan's highly integrated electronics supply chain.

The creation of the Taiwan's knowledge economy does not mean a complete shift from one manufacturing strategy to another. Rather, the Si-Soft strategy builds on the existing industrial infrastructure and utilizes existing industrial strengths [5]. On one hand, the traditional strengths were built from the Si-Hard (silicon hardware) manufacturing and manufacturing services. Over the last 20 years, government, industry, and academic research efforts have yielded fast-follow technology development and transfer in the areas of micro-electronic machines (MEMs), nano-device technology, material science, manufacturing, engineering and the pure sciences. In many cases, such as in the development of semiconductor manufacturing and packaging, the technology does not follow but leads the world market. On the other hand, the Si-Soft Project places emphasis on product development that upgrades the existing manufacturing base. The products that best match the existing manufacturing capabilities are information appliances (personal digital assistants), energy products (batteries), electrooptical devices (liquid crystal displays (LCDs), optical communication devices), Internet devices (routers, switches), system on a chip (SoC)-based products, and bio-medical products (bio-chips). The development of these special classes of products cannot be realized without a well-developed Si-Hard supply chain.

The Taiwan government has been very generous in investing in and encouraging the electronics manufacturing. The first government sponsored venture began with UMC, a NT\$ 110 million investment. 
UMC remains to this day a privately owned electronics-manufacturing leader. TSMC is another case in point and in 1987 received NT\$ 300 million from both private and public sources. Most recently, the Taiwan government has invested over NT\$ 150 billion in IC development, NT\$30 billion in LCD manufacturing, and NT\$ 7 billion in thin-film (GaAs and EpI) technologies. The scale of Si-Hard investment, over NT\$ 180 billion, represents about two-thirds of the total planned investments for Si-Soft. The Si-Soft Project predicts over NT\$ 300 billion revenue from these and other planned investments.

The experience learned from the development of Si-Hard companies is that public financed investment will have greater success if managed by industry professionals. Government controlled enterprises tend to remain isolated from market forces and can become a public burden. Thus, Si-Soft insures that $70 \%$ of the investments are solicited from private sources and $30 \%$ are derived from government sources. The schedule of investment will be increased in the year 2003 to support further development of innovative design capabilities. Revenue yields from the investment are targeted to reach the NT\$30 billion level in the year 2005, particularly from the sale of virtual components (intellectual property blocks) used in SoC applications. The Si-Soft investment will further stimulate at least NT\$ 300 billion revenue in the year 2010 from the marketing of innovative products.

As world electronics market develops shifts in production invariably occur and manufacturing facilities move to take advantage of materials and labor. Mainland China is showing increased manufacturing development whereas other regions in Asia are seeing a boom in service and intellectual property development. That is, manufacturing growth in one area is complemented by the growth of knowledge-based economies in other areas. China began semiconductor production from mid-range technology $(0.25 \mu \mathrm{m})$ and will migrate to $0.18 \mu \mathrm{m}$ this year. The manufacturing advances in China are complementing and supporting the market shifts in Taiwan. Taiwan is phasing out mid-range manufacturing and is producing chips using advanced processes at the 0.13 and $0.1 \mu \mathrm{m}$ levels. In addition to these changes, the Taiwan semiconductor industry is shifting toward the creation of intellectual property, the innovation behind the products manufactured in the increasingly sophisticated and expensive semiconductor fabrication facilities. Further, the creative design of ICs, and the ability to build a SoC by integrating blocks of intellectual property is fueling the growth of Taiwan's knowledge based economy. These changes to the economy (Fig. 3) are encouraged and supported by the National Si-Soft

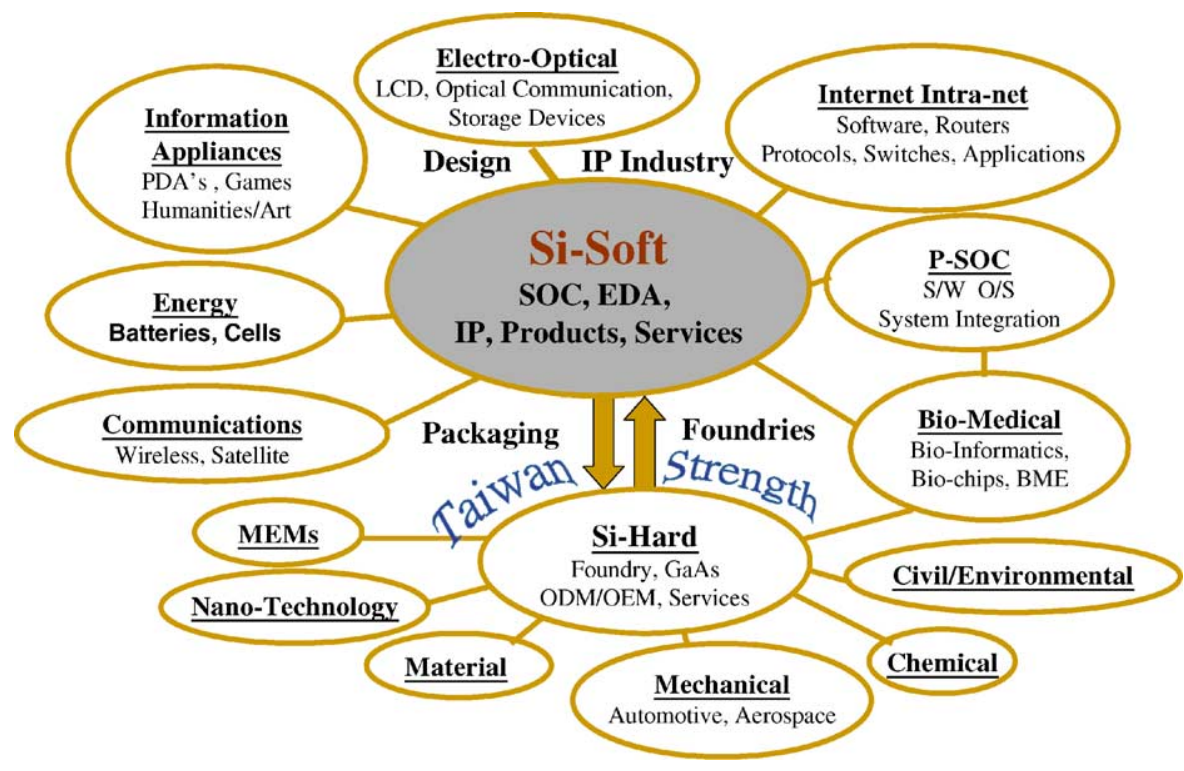

Fig. 3. Building out the Taiwan electronics industry supply chain with Si-Soft. 
Project with funding from the Ministry of Economic Affairs (MOEA).

The goal of the National Si-Soft Project is to develop the SoC infrastructure for domestic as well as international production facilities. These new facilities will enable the international supply chain to source designs, mix-and-match intellectual property, manufacture, and test deep-sub micron ICs. The Si-Soft Project is divided into five parts.

- Innovative product designs: Three product lines will demonstrate SoC solutions and the excellent design environment in Taiwan.

- Silicon intellectual property (SIP) development: Customers will be provided with a broad range of SIPs needed for the three product lines mentioned above. All SIPs will be verified for robustness and classified into gold, silver and bronze categories for customers one-stop shopping.

- Electronic design automation (EDA) flow integration: New design platforms will be developed to satisfy the ever increasing demand for software to test and verify virtual component designs for re-use.

- SIP mall: A variety of SIPs will be put together for customers to quickly select and integrate the SIPs into SoC designs.

- Design service solutions: A new design-service industry will be developed and will be used to appraise the performance of the SoC Project. In addition, the construction of a SoC industrial park is proposed to better serve customers around the clock and around the world.

In summary, the Si-Soft Project will provide new types of electronic design automation software, IP design flow integration, IP trade services, as well as develop long-distance collaborative design networks. With the creation of a leading SoC environment in Taiwan, the global electronics supply chain will gain a better source of ideas and products for consumers.

\section{References}

[1] M.M.K. Lin, C.V. Trappey, The development of Taiwan's IC industry, IEEE Trans. Comp. Packag. Manuf. Technol. 20 (4) (1997) 235-242.

[2] C.V. Trappey, H. Chen, Made by Taiwan, in: The Integrated Circuit Industry: A Technological Powerhouse, World Scientific, Singapore, 2001, ISBN 981-02-4770-6.

[3] C.V. Trappey, The Taiwan Electronics Market, Hwa-Tai Publishing, Taipei, 2000, ISBN 957-609-264-7.

[4] C.Y. Changm, P.L. Yu, Made by Taiwan, in: The Development of Taiwan's IC Industry: An Overview, World Scientific, Singapore, 2001, ISBN 981-02-4770-6.

[5] http://www.eic.nctu.edu.tw/SOC/button.htm, August 2002 (in Chinese). 